\title{
Literatura e Arte no ensino de Ciências: a formação de professores para alunos com deficiências visuais no Ensino Fundamental ${ }^{+}$
}

\author{
Maria da Conceição Barbosa-Lima ${ }^{1}$ \\ Universidade do Estado do Rio de Janeiro \\ Instituto Oswaldo Cruz \\ Rio de Janeiro - RJ
}

\section{Resumo}

Trata o presente trabalho de uma proposta de formação de professores inclusivistas, ou seja, aqueles que acreditam que alunos sem quaisquer problemas detectados e alunos com quaisquer deficiências, possam estudar em escolas regulares. Fazemos uma conjugação entre Arte, especialmente a Literatura, no formato de histórias infantis para o ensino de tópicos elementares de Física nos anos iniciais de escolarização. Consideramos essencial o ensino equânime dos alunos considerados sem problemas aparentes e aqueles com deficiência visual. Apresentamos nossas atuações anteriores no campo de estudo da conjugação entre Literatura e Física e Arte Plástica e Física, como exercicios para chegarmos ao ponto em que hoje nos encontramos. Estamos certos de que os professores necessitam exercitar sua imaginação e criatividade, tanto para elaborar as histórias, quanto para avaliar sua compreensão, no que diz respeito ao tópico em pauta. Relatamos o que esperamos da formação de licenciandos de nossa Universidade e os tópicos do Manifesto CiênciArte, que seguimos em nossa prática, tanto na formação, quanto em nossa atuação profissional.

Palavras-chave: Literatura e Arte no Ensino de Ciências; Histórias Infantis; Formação de Professores; Alunos com Deficiência Visual.

\footnotetext{
${ }^{+}$Literature and Art in Science teaching: teacher training for students with visual impairments in Elementary School

* Recebido: fevereiro de 2020. Aceito: abril de 2020.

${ }^{1}$ E-mail: mcablima@uol.com.br
} 


\begin{abstract}
This work proposes the training of inclusive teachers, that is, those who believe that students without any detected problems and students with any disability, can study in regular schools. We used Art, especially Literature, in the format of children's stories to teach elementary topics in Physics in the early years of schooling. We consider the equitable teaching of students without apparent problems and those with visual impairment, to be essential, based on our previous studies, combining Literature and Physics, and Plastic Art and Physics. Such studies led us to the point where we find ourselves to be sure that teachers need to exercise their imagination and creativity to elaborate the stories and evaluate their understanding regarding the topic at hand. We herein also report what we expect of the training of undergraduate students at our University, and the topics of the CienciArt Manifest, that we follow in our practice, both in training and in our professional performance.
\end{abstract}

Keywords: Literature and Art in Science Teaching; Children's Stories; Teacher Training; Visually Impaired Students.

\title{
I. Introdução
}

Por muito tempo, Arte, aí incluindo a Literatura, e Ciência eram campos separados e seus adeptos quase inimigos, como podemos perceber pelos escritos de C.P. Snow, em seu livro: “As Duas Culturas”, publicado pela primeira vez em 1959.

Os adeptos da Arte julgavam os cientistas como seres quase sem alma, sem a necessária delicadeza para apreciar as obras de arte. Enquanto isso, os cientistas julgavam os artistas seres de outro planeta, que viviam com os pés no mundo da lua, incapazes de raciocínios lógicos.

Pobres senhores, pois nenhum deles era capaz de perceber que tanto para a Arte quanto para a Ciência, é necessário e fundamental ter criatividade, audácia e, principalmente, imaginação.

Com o tempo, timidamente, começou o movimento de reconhecimento e de aproximação entre as duas culturas. Talvez a aproximação mais contundente seja o surgimento dos fractais, trabalho de cientistas, que são verdadeiras obras de arte da natureza. Mas não foi estancada aí a aproximação. Passaram-se anos desde o livro de Snow até o lançamento do Manifesto Ciência e Arte, em 2011, que mais tarde tornou-se CienciArte, assinado por Bob Root-Bernstein, Todd Siler, Adam Brown e Kenneth Snelson: 
1) Tudo pode ser compreendido através da arte, mas esse entendimento é incompleto.

2) Tudo pode ser compreendido através da ciência, mas esse entendimento é incompleto.

3) CienciArte nos permite alcançar uma compreensão mais completa e universal das coisas.

4) CienciArte envolve a compreensão da experiência humana da natureza pela síntese dos modos artístico e cientifico de investigação e expressão.

5) CienciArte funde a compreensão subjetiva, sensorial, emocional e pessoal com a compreensão objetiva, analítica, racional e pública.

6) CienciArte incorpora a convergência de processos e habilidades artística e científica, e não a convergência de seus produtos.

7) CienciArte não é arte + ciência ou arte-e-ciência ou arte/ciência, nos quais os componentes retêm suas distinções e compartimentalização disciplinares.

8) CienciArte transcende e integra todas as disciplinas ou formas de conhecimento.

9) Aquele que pratica CienciArte é simultaneamente um artista e um cientista; $e$ uma pessoa que produz coisas que são tanto artísticas quanto científicas simultaneamente.

10) Todo grande avanço artístico, impacto tecnológico, descoberta científica e inovação médica, desde o início da civilização, resultou de um processo de CienciArte.

11) Todo grande inventor e inovador na história foi um praticante de CienciArte.

12) Devemos ensinar arte, ciência, tecnologia, engenharia e matemática como disciplinas integradas, não separadamente.

13) Devemos criar currículos baseados na história, na filosofia e na prática de CienciArte, usando as melhores práticas da aprendizagem experimental.

14) A visão de CienciArte é a re-humanização de todo o conhecimento.

15) A missão de CienciArte é a reintegração de todo o conhecimento.

16) O objetivo de CienciArte é cultivar o novo renascimento (ARAÚJO-JORGE et al., 2018, p. 26-7).

Então, a Arte e a Ciência passaram a ter uma nova condição. Elas passaram a poder ser imbricadas, possibilitando o entendimento, a compreensão das mais variadas coisas do mundo, além de permitirem ou mesmo estimularem a utilização da criatividade e da imaginação.

São diversas as formas do fazer artístico. Para falarmos da Ciência do sábio, da Ciência do professor - aquela que é levada para as salas de aula - e da Ciência do cidadão comum, consumidor de seus feitos e efeitos, Arte e Ciência podem unir-se, seja em um quadro de Vermeer (BARBOSA-LIMA; QUEIROZ; SANTIAGO, 2007), ou um quadro de Remedios Varo, podendo passar a ser lido, quase que como se um texto fora (BARBOSALIMA, 2008). Assim, um trabalho a ser realizado no nível escolar fundamental, quando as crianças estão em uma faixa etária baixa, começando a compreender o mundo em que vivem, pode apoiar-se em histórias infantis. 


\section{O que já fizemos e o que pretendemos realizar}

Estudamos a relação entre a literatura e o ensino de ciências, mais especificamente a Física, primeiro através da obra de Fernando Pessoa, com o artigo "Quando o sujeito se torna pessoa: uma articulação possível entre poesia e ensino de Física”, com a colaboração de Lins de Barros e Terrazzan. Em seguida, foi a vez de usarmos o filme e o livro: "A moça com brinco de pérola", baseados no quadro homônimo de Vermeer, associando-nos a Queiroz e Santiago. Os estudos sobre o filme e o texto deram o destaque para as conceituações Físicas nele envolvidas propiciando debates com licenciandos em Física, e a elaboração de sequências didáticas embasadas tanto no filme quanto no livro.

Dessas experiências, concluímos que a aliança entre Literatura, Arte e Ciência é possível e proveitosa. Por isso, passamos a nos apoiar no Manifesto CienciArte, elaborado por Bob Root-Bernstein, Todd Siler, Adam Brown e Kenneth Snelson.

Hoje, trabalhamos com a narrativa em forma de histórias infantis, como meio de ensinar ciências e alguns tópicos de Física para turmas inclusivas. Uma das nossas grandes preocupações é a formação de professores com condições mínimas de atender a alunos com deficiência visual no Ensino Fundamental, uma vez que esses estudantes estão cada dia mais presentes em nossas escolas regulares. Por isso, neste momento, estamos elaborando um material didático, para ser usado em cursos de Licenciatura em Física, cuja implementação esperamos obter pistas/indicações para a formação de professores inclusivistas ${ }^{2}$, capazes de empregar sua imaginação para criar novas histórias que auxiliem no ensino de conceitos físicos a este público. Neste trabalho relatamos algumas experiências já consagradas e sugerimos que outros professores criem novos textos.

\section{Por que usar uma história?}

Em Barbosa-Lima, Barros e Terrazzan (2004), encontramos uma citação de Zanetic (1998, p. 1), em que ele afirma: "associar ciência e imaginação, trabalho científico e trabalho literário, ciência e arte, enfim, parece ainda muito estranho, mesmo quando aderimos ao paradigma da interdisciplinaridade".

Mas as histórias infantis, de acordo com o Manifesto CienciArte, não devem ser vistas como um objeto interdisciplinar. Sendo a formulação, a criação da história que nos interessa, e não a aliança de seus produtos finais, uma história infantil deve ser considerada como um objeto único, que congrega o fazer arte e o fazer ciência, com a convergência de processos e habilidades artística e científica e não a convergência de seus produtos.

Então, desejamos formar professores de Física que possam empregar CienciArte em suas aulas regulares, em turmas inclusivas, para ensinar conceitos de Física através de

\footnotetext{
2 Denominamos professores inclusivistas àqueles que costumeiramente ministram aulas para pessoas com deficiências, procurando sempre, adequar os materiais e os métodos de suas aulas da melhor forma para atingir a equidade.
} 
histórias infantis. Claro está que consideramos as histórias infantis como um elemento artístico, literário e, ainda mais quando se coloca como mote da história conceitos de Física, sua escrita deve ser cuidadosa e precisa. No entanto, ao mesmo tempo, não deve perder de vista o rigor que a Ciência exige. Dessa forma, as simplificações devem ser alijadas do texto nesse tipo de material.

Antes de qualquer coisa, é conveniente comentar dois pontos relevantes. Primeiro, mostrar ao futuro professor que todas as crianças, deficientes visuais ou não, pensam e imaginam, e, segundo, mostrar que a estratégia de ensino construída para ensinar a um aluno com deficiência visual será também um agente facilitador para a construção do conhecimento para o estudante normovisual ${ }^{3}$ (TATO, 2016, 2019; CAMARGO, 2012). Quanto mais material for fornecido a essas crianças, mais imaginação elas terão para abstrair e construir suas imagens mentais, durante o processo de aprendizagem.

O professor precisará, ele também, dar asas à sua imaginação e criatividade. De acordo com Vigotski ${ }^{4}$, não há separação clara entre imaginação e criatividade. Assim, ressaltamos que a imaginação, por ser uma importante característica a ser explorada pelo professor que deseja elaborar uma história com conceitos de Física, é necessária e imprescindível para a construção de um cenário adequado à evolução do conceito físico que se deseja apresentar ao leitor. Além disso, ainda segundo Vigotski, é importante que a história aguce a curiosidade dos alunos porque:

(...) Quanto mais a criança viu [ele está falando de uma criança qualquer], ouviu e vivenciou, mais ela sabe e assimilou; quanto maior a quantidade de elementos da realidade de que ela dispõe em sua experiência (...), mais significativa e produtiva será a atividade de sua imaginação (2012, p. 23).

A tendência geral, no início dos cursos que tratam do ensino de Física para alunos com deficiência visual é a incredulidade na capacidade intelectual destes alunos (BARBOSALIMA; CATARINO, 2019). Porém, no decorrer das disciplinas, este velho preconceito é superado e percebe-se que a cognição do indivíduo com deficiência visual é equivalente à do estudante normovisual. Mas, enquanto os normovisuais são estimulados pela imitação dos mais velhos nos afazeres da vida, em geral pela visão, as pessoas com deficiência visual precisam ser estimuladas através de outros canais sensoriais, ou seja: pelo tato, pelo olfato, pela audição e pelo paladar (SOLER, 1999). Recorrendo mais uma vez a Vigotski (2009), percebemos ser a linguagem, através da fala, o estímulo que se torna o canal privilegiado de contato, principalmente do indivíduo cego, com o meio que o rodeia.

\footnotetext{
3 Normovisual é chamado o indivíduo com visão normal.

4 Notação adotada para o nome do autor de acordo com a tradução direta do idioma russo realizada por Zoia Prestes.
} 
Sendo assim, podemos considerar que a contação de histórias é um recurso produtivo, posto que a criança cega terá que elaborar seus modelos de cenário e personagens, baseados em suas experiências sensoriais, diferentes das dos demais alunos.

Nas palavras de Vigotski (2009):

[...] a imaginação adquire uma função muito importante no comportamento e no desenvolvimento humanos. Ela transforma-se em meio de ampliação da experiência de um indivíduo porque, tendo por base a narração ou a descrição de outrem, ele pode imaginar o que não viu, o que não vivenciou diretamente em sua experiência pessoal. A pessoa não restringe ao círculo e a limites estreitos de sua própria experiência, mas pode aventurar-se para além deles, assimilando, com a ajuda da imaginação, a experiência histórica ou sociais alheias. Assim configurada, a imaginação é uma condição totalmente necessária para quase toda atividade humana.

[...] há uma dependência dupla e mútua entre imaginação e experiência. Se no primeiro caso a imaginação apoia-se na experiência, no segundo é a própria experiência que se apoia na imaginação (p. 25).

Assim, se a criatividade surge em acordo com a imaginação, quanto mais material, quanto mais alimentada é a imaginação, mais criativo é o indivíduo, e, nas palavras do teórico:

A atividade criativa da imaginação depende diretamente da riqueza e da variedade das experiências prévias das pessoas porque esta experiência fornece o material a partir do qual os produtos da imaginação são construidos. Quanto mais rica a experiência de uma pessoa mais rico é o material que a imaginação poderá acessar (VIGOTSKI, 2009, p. 14).

\section{E o professor?}

O que fazer com sua imaginação? O dito anteriormente sobre a atividade criativa da imaginação significa dizer que ele deve se permitir imaginar, seja para o passado, relembrando experiências vividas, ou para o futuro, fazendo previsões e desta maneira será, muito provavelmente, um sujeito criativo.

Se o professor, mesmo aquele que tem pouca ou nenhuma aptidão para criar uma história, souber explorá-la, verá que ela é útil para, como afirmam Torres e Tettamanzy (2008, p. 3), atingir objetivos diversos:

O principal objetivo em contar uma história é divertir, estimulando a imaginação, mas, quando bem contada, pode atingir outros objetivos, tais como: educar, instruir, conhecer melhor os interesses pessoais, desenvolver o raciocínio, ser ponto de partida para trabalhar algum conteúdo programático, assim podendo aumentar o interesse pela aula ou permitir a auto identificação, favorecendo a compreensão 
de situações desagradáveis e ajudando a resolver conflitos. Agrada a todos sem fazer distinção de idade, classe social ou circunstância de vida.

Já em relação à Ciência, quem vem em nosso auxílio é Fiolhais (2008), quando afirma que é:

[...] necessário desfazer a ideia feita segundo a qual a imaginação é estranha à ciência. De facto, é necessária uma grande imaginação, por vezes como aconteceu no caso da teoria da relatividade uma imaginação extraordinária, para realizar o empreendimento científico. A missão do cientista consiste na descoberta do mundo real, um mundo que é único e que pode ser contrastado com os muitos e variados mundos criados pela sua imaginação (FIOLHAIS, 2008, p. 2).

Jay Lemke, em um artigo datado de 2006, em que discute os objetivos da educação científica para o século XXI, afirma: “[...] Ao mesmo tempo, reconhecer a importância da narrativa como meio de comunicação e de aprendizagem e restituir-lhe seu lugar proeminente na educação científica [...]" (2006, p. 8).

Nesta mesma página, encontramos outro conselho de Lemke: “[...] Reconhecer a importância da linguagem como meio primário para o raciocínio e a conceitualização em ciências, mas também ajudar aos estudantes a raciocinar mais efetivamente sobre assuntos científicos [...]" (idem).

Uma única história tem o poder de encantar, tanto alunos quanto professores, e obter respostas que nos levem a conhecer a construção do conhecimento científico dos alunos, assim como a segurança no ensino de nossos licenciandos, já que os comentários e relatos dos alunos são na maioria das vezes inesperados.

Como exemplo, podemos destacar o de Monteiro, Hallais e Barbosa-Lima (2019), intitulado: "A Física da gangorra: Ensino de Física e história para crianças", em que o conceito de equilíbrio é discutido, através das observações de Benjamin, o personagem principal da história, frente ao funcionamento de uma gangorra. Apresentado no Simpósio nacional de Ensino de Física, em Salvador, Bahia.

\section{Como deve ser a formação de professores capazes de usar a Arte e a Literatura?}

Antes de mais nada, se desejarmos formar professores que sejam capazes de ministrar aulas para turmas que tenham alunos com deficiência visual estudando lado a lado com normovisuais, mais importante ainda é que eles sejam professores reflexivos, ou seja, que tenham possibilidade de refletir na ação e sobre a ação (PERRENOUD 2007, SCHÖN, 2000). E, como nas palavras de Perrenoud, que sejam professores profissionais:

(...) um profissional (...) identifica o problema, apresenta-o, imagina e aplica uma solução e, por fim, garante seu acompanhamento. Ele não conhece de antemão a 
solução dos problemas que surgirão em sua prática; deve construi-la ao vivo (...) (PERRENOUD, 2007, p. 11, grifo do autor).

Mas, para trabalhar com histórias infantis é importante que o professor conheça e aplique o Manifesto CienciArte.

Então, deve-se considerar que apenas atividades artísticas, como por exemplo, a execução de maquetes e/ou aparatos, por mais bonitos que sejam, oferecerá um entendimento incompleto, como preconiza o primeiro item do Manifesto, "Tudo pode ser compreendido através da arte, mas esse entendimento é incompleto". Da mesma forma, será incompleto o entendimento quando, ainda que bem elaborados os experimentos oferecidos, não forem agradáveis aos sentidos. Por exemplo, ao usarmos um tubo de Kundt, o estudante compreenderá o fenômeno, mas este entendimento será incompleto, principalmente para os alunos com deficiência visual.

Obedecendo ao item terceiro do Manifesto, "CienciArte nos permite alcançar uma compreensão mais completa e universal das coisas se pudermos aliar a execução de materiais", seja pelos estudantes, seja apresentados prontos pelo professor, bem feitos, bemacabados, agradáveis aos sentidos e, além disso, que respondam aos experimentos de uma maneira cientificamente correta, alcançaremos a compreensão total do conceito estudado. São bastante propícios para uma turma inclusiva, outros dois itens do Manifesto: o quarto deles, que indica que CienciArte envolve a compreensão da experiência humana da natureza, pela síntese dos modos artístico e científico de investigação e expressão; e o quinto, que indica a fusão da compreensão subjetiva, sensorial, emocional e pessoal com a compreensão objetiva, analítica, racional e pública.

Relembrando que sugerimos o emprego de histórias infantis com conteúdo de Física, que raramente são encontradas no mercado editorial, muito provavelmente caberá ao docente e/ou os alunos, se já dominarem alguma forma de expressão gráfica, a escrita ou o desenho, a elaboração delas. Mas esse tipo de histórias deve respeitar o que o item seis do Manifesto CienciArte que indica: a incorporação da convergência de processos e habilidades artística e científica, e não a convergência de seus produtos. Ou seja, não se trata de colocar conceitos científicos em uma dada história já existente, como indica o item sete. É necessária a criação habilidosa de cenários e situações que sirvam de forma convergente para o conteúdo que se deseja transmitir, com a beleza da arte aliada à rigorosidade da ciência.

Da mesma maneira que não é necessário que nos prendamos à nossa ciência, afinal aos professores cabe a tarefa da formação de cidadãos, portanto, falar do meio ambiente, da sociedade e da tecnologia, por exemplo, é esperado e necessário, porque dessa forma oferecemos aos nossos estudantes uma visão ampliada de mundo. 


\section{A avaliação que propomos}

Se nós propomos uma aula apoiada na contação de histórias infantis, esperamos que a avaliação da compreensão e do entendimento dos conceitos nelas contidos sejam diferenciados das habituais provas, com exercícios para serem solucionados comparativamente entre os estudantes.

A avaliação que propomos está apoiada nas rodas de conversa, na argumentação dos alunos, entre eles e entre eles e o professor, e ainda na solicitação de resumos da história, desenhos ou ambos.

No caso dos desenhos, devemos levar em conta que crianças do ensino fundamental, por exemplo, desenham o que sabem a respeito do assunto. Então, é comum que encontremos elementos gráficos diferentes daqueles contados na história, principalmente se ela for contada com apoio visual de gravuras, álbuns seriados e afins.

É conveniente lembrar que alunos com deficiência visual raramente desenham, alguns fazem garatujas. Neste caso cabe ao professor solicitar que o desenho seja explicado verbalmente para que o aluno sinta-se incluído na tarefa.

Em Barbosa-Lima (2001, apud PILAR 1996), desenho é “o trabalho gráfico da criança que não é resultado de uma cópia, mas da construção e da interpretação do objeto pelo sujeito" (p. 33).

Consideramos que assim como quando a leitura não é feita solitariamente, ao ouvir uma história, a imaginação dos estudantes alça voo. Tomando leitura por audição, podemos citar o trecho a seguir para expor nossas ideias:

Sempre que nos propomos a realizar uma leitura nunca o fazemos solitariamente. Tudo o que vivemos, que pensamos, que esperamos, enfim, todas as vozes que povoam nosso ser cultural interpretam a leitura que está sendo feita junto conosco (BAKHTIN, 1997). Quero dizer com isto, de acordo com os ensinamentos bakhtinianos, que nossa ideologia, nossas frustrações, nossas crenças, nossas emoções vividas e esperadas estarão presentes ao ato de leitura. Em outras e mais sintéticas palavras, nossa cultura estará lá, fazendo com que leiamos de acordo com o já vivido, para concordar ou discordar (BARBOSA-LIMA, 2008, p. 1).

Desta forma, ao ouvirem uma história, nossos alunos trarão para ela contribuições de suas vivências, crenças, frustrações, emoções, ilusões e outros tantos sentimentos, sejam eles normovisuais ou não.

Ou como afirmaria Bakhtin, “[...] não há enunciados isolados. Um enunciado pressupõe sempre enunciados que o precederam e aqueles que o sucederão; ele nunca é o primeiro, nem o último; ele é apenas um elo duma cadeia e não pode ser estudado fora dessa cadeia" (1992, p. 375). 
Lendo o trabalho de Silva (2010), ela nos recorda que a comunicação estética é realizada através do dialogismo, analogamente ao processo da interação verbal cotidiana, na fala. Então, numa obra de literatura ou aqui, nas histórias infantis, os alunos respondem à história que está sendo contada, a um diálogo, mesmo que permaneça mudo, entre o contador e o ouvinte.

\section{Considerações finais}

Acreditamos que as aulas de ciências, mesmo para os anos iniciais de escolarização, devem apresentar conteúdos de Física de maneira a aproximar as crianças desta ciência. É claro que o formalismo e o formulismo, ou seja, aquela profusão de fórmulas, que tanto agrada a alguns professores, deve ser desconsiderada, tanto porque é irrelevante para a metodologia empregada, quanto é inadequada para o nível de escolaridade que estamos desejando atingir. Porém, a conceituação, mesmo que ainda perdure o conceito vivencial nas mentes das crianças, deve e pode ser apresentado, desde, é claro, que de uma maneira palatável, intrigante, estimulante e conforme suas faixas etárias.

Nossa proposta de formar professores capazes de cumprir com estas exigências tem obtido sucesso, posto que o ensino de Física é iniciado ainda quando o aluno está entre nove e dez anos de idade, ou seja, aceita de bom grado ouvir uma boa história e ser avaliado em função do que foi ouvido, ainda mais se ele tem a possibilidade de trocar ideias com seus pares antes da avaliação e esta pode ser da forma que ele venha a escolher: redação ou desenho.

Nossa experiência com a elaboração de histórias infantis e sua contação tanto para alunos normovisuais quanto para alunos com deficiências visuais têm nos indicado ser este um caminho promissor para a apresentação da Física em níveis iniciais de escolarização.

\section{Referências}

ARAÚJO-JORGE, T. et al. Ciênciarte no instituto Oswaldo Cruz: 30 anos de experiência na construção de um conceito interdisciplinar Ciência e Cultura, v. 70, n. 2, São Paulo, abr./jun 2018.

BAKHTIN, M. Estética da criação verbal. São Paulo: Martins Fontes, 1992.

BARBOSA-LIMA, M. C. Explique o que tem nessa história. 2001. Tese. (Doutorado) Faculdade de Educação, Universidade de São Paulo, São Paulo.

BARBOSA-LIMA, M. C.; BARROS, H. L. de; TERRAZZAN, E. A. Quando o sujeito se torna pessoa: uma articulação possível entre poesia e ensino de física Ciência \& Educação, v. 10, n. 2, p. 291-305, 2004. 
BARBOSA-LIMA, M. C.; QUEIROZ, G.; SANTIAGO, R. B. Ciência e Arte: Veermeer, Huygens e Leeuwenhoek. Física na Escola, v. 8, n. 2, 2007.

BARBOSA-LIMA, M. C. Um quadro para ser lido... Ciência em Tela, v. 1, n. 1, 2008.

BARBOSA-LIMA, M. C.; CATARINO, G. F. C. É importante estudar física se você é deficiente visual? As respostas de estudantes recém-ingressos na universidade. In: SIMPÓSIO NACIONAL DE ENSINO DE FÍSICA, XXIII, 2019, Salvador, Bahia. Atas... Disponível em: $<$ http://www.sbfisica.org.br/ snef/xxiii/>.

CAMARGO, E. P. Saberes docentes para a inclusão do aluno com deficiência visual em aulas de física. 1. ed. São Paulo: UNESP Editora, 2012.

FIOLHAIS, C. Imaginação, Ciência e Arte. Disponível em:

$<$ https://www.researchgate.net/publication/268263035_Imaginacao_ciencia_e_arte/reference> Acesso em: 01 jul. 2018.

LEMKE, J. L. Investigar para el futuro de la educación científica: nuevas formas de aprender, nuevas formas de vivir. Enseñanza de las Ciencias, v. 24, n. 1, p. 5-12, 2006.

MONTEIRO, A. B. F.; HALlAIS, S. de C.; BARBOSA-LIMA, M. C. A física da gangorra: ensino de física e história para crianças. In: SIMPÓSIO NACIONAL DE ENSINO DE FÍSICA, XXIII, 2019, Salvador, Bahia. Atas... Disponível em: $<$ http://www.sbfisica.org.br/ snef/xxiii/>.

PERRENOUD, P. A prática reflexiva no ofício de professor: profissionalização e razão pedagógica. Tradução: Claudia Schilling. São Paulo: Artmed, 2007.

SCHÖN, D. A. Educando o profissional reflexivo: um novo design para o ensino e a aprendizagem. Tradução: Roberto Cataldo Costa. São Paulo: Artmed, 2000.

SILVA, M. C. Infância e literatura. Rio de Janeiro: EdUERJ, 2010.

SOLER, M. A. Didáctica multisensorial de las ciencias: Un nuevo método para alumnos ciegos, deficientes visuales, y también sin problemas de visión. Barcelona: Paidós, 1999.

SNOW, C. P. As duas culturas. Rio de Janeiro: Gradiva do Brasil, 2004. 
TATO, A. L. Atividades Multissensoriais para o Ensino de Física. 2016. 171f. Tese. (Doutorado em Ensino de Ciências) - Programa de Pós-Graduação Interunidades em Ensino de Ciências, Universidade de São Paulo.

TATO, A. L. Material de Equacionamento Tátil para usuários do Sistema Braille. 2009. 100 f. Dissertação (Mestrado em Ensino de Ciências) - CEFET/RJ, Programa de Pósgraduação em Ensino de Ciências e Matemática, Rio de Janeiro.

TORRES S. M.; TETTAMANZY, A. L. L. Contação de histórias: resgate da memória e estímulo à imaginação. Nau Literária, Porto Alegre, v. 4, n. 1, p. 1-7, 2008.

VIGOTSKI, L. S. Imaginação e criação na infância. Tradução: Prestes, Z. R. São Paulo: Ática, 2009.

VIGOTSKI, L. S. El niño ciego. In: Obras escogidas - Tomo V. Fundamentos de defectologia. Madrid: Machado, 2012.

ZANETIC, J. Ensino de Física através de sua história e filosofia para quem gosta de literatura. In: ENCONTRO DE PESQUISA EM ENSINO DE FÍSICA, VI, 1998, Florianópolis. Atas... Florianópolis: Sociedade Brasileira de Física, 1998. 